\title{
The effects of continuing and discontinuing smoking on the development of chronic kidney disease (CKD) in the healthy middle-aged working population in Japan
}

\author{
Yuka Noborisaka • Masao Ishizaki • Yuichi Yamada • \\ Ryumon Honda • Hitoshi Yokoyama • Masaru Miyao • \\ Masaji Tabata
}

Received: 17 January 2012/Accepted: 30 April 2012/Published online: 24 May 2012

(c) The Japanese Society for Hygiene 2012

\begin{abstract}
Objectives The strength of the association between smoking and the development of chronic kidney disease (CKD) in the healthy middle-aged working age population has not been established.

Methods This was a retrospective 6-year observational study involving 4,121 male and 2,877 female workers who were free of primary kidney disease, diabetes mellitus, severe hypertension, and the signs and symptoms of CKD. Proteinuria was detected by a dipstick method, and glomerular filtration rate (GFR) was estimated by the equation of the Japan Society of Nephrology.

Results Sixty men $(1.5 \%)$ and 21 women $(0.7 \%)$ developed proteinuria over the 6 years of the study. Irrespective of sex, in comparison with non-smokers, those who continued smoking showed an odds ratio (OR) of 2.52
\end{abstract}

Y. Noborisaka $(\varangle) \cdot$ M. Ishizaki · Y. Yamada Department of Social and Environmental Medicine, Kanazawa Medical University School of Medicine,

1-1 Daigaku, Uchinada, Kanazawa, Ishikawa 920-0293, Japan

e-mail: hygiene@kanazawa-med.ac.jp

R. Honda

Kanazawa Medical University School of Nursing,

Uchinada, Kanazawa, Ishikawa, Japan

H. Yokoyama

Division of Nephrology, Kanazawa Medical University School

of Medicine, Uchinada, Kanazawa, Ishikawa, Japan

\section{Miyao}

Graduation School of Information Science,

Nagoya University, Nagoya, Aichi, Japan

M. Tabata

Ishikawa Health Service Association,

Kanazawa, Ishikawa, Japan with a $95 \%$ confidence interval (CI) of 1.50-4.25 for developing proteinuria while those who quit smoking showed an OR of 1.29 (95\% CI 0.48-3.42), following adjustment for confounders. Among the study population, 443 men $(10.7 \%)$ and 356 women $(12.4 \%)$ developed a GFR of $<60 \mathrm{~mL} / \mathrm{min} / 1.73 \mathrm{~m}^{2}$, corresponding to stage III CKD. Continuing smokers had a low OR $(0.74,95 \% \mathrm{CI}$ 0.60-0.90) for developing a low GFR, as well as a higher mean GFR than non-smokers. The reduction in GFR during the 6-year study period was not different between smokers and non-smokers, but it was larger in those who developed proteinuria than in those who did not, irrespective of smoking.

Conclusions Continuing smokers showed a twofold or more higher risk of developing proteinuria. Discontinuation of smoking substantially reduced the risk. A longer observational period may be required to detect the smoking-induced risk of developing stage III CKD in the middle-aged working population.

Keywords Smoking - Chronic kidney disease .

Proteinuria - Estimated glomerular filtration rate $\cdot$ Healthy person

\section{Introduction}

Cigarette smoking has been demonstrated to cause chronic kidney disease (CKD) characterized by proteinuria and/or a reduced glomerular filtration rate (GFR). The most susceptible are patients with a preceding renal dysfunction due to diabetes mellitus (DM), primary kidney diseases, or hypertension, followed by members of the general public in both the community and workplace settings who do not have such a renal dysfunction [1-4]. The strength of the 
association between smoking and the development of CKD in generally healthy people in the general population, however, has not yet been fully established because of the vast heterogeneity in the source populations and the outcome measurements used in the previous studies [5].

The number of patients with end-stage kidney disease (ESKD) requiring kidney transplantation or hemodialysis has been increasing rapidly throughout the world, from 430,000 to $2,100,000$, a nearly fivefold increase, in the last two decades. In Japan, some 300,000 patients are currently undergoing dialysis therapy, while some 13,300,000 CKD patients are estimated to be pre-ESKD [6]. Therefore, the prevention of CKD should be a target of health-promoting organizations/programs given that it is a common disease among the general population, including the working population. However, the strength of the association between smoking and the development of CKD is vague, especially in working populations [7] that are mainly composed of middle-aged adults who are probably less vulnerable to the toxic effects of smoking than community populations consisting of many elderly persons aged 60 years or older.

Furthermore, many of the previous studies carried out in workplaces were cross-sectional in design [8-12]. The few longitudinal studies conducted in workplaces that have been conducted to date are limited to a small number of subjects [13] or to a short observational period [14]. Therefore, long-term and large-scale observational studies are required to determine the strength of the association in populations recruited from workplaces. In the study reported here, we analyzed 6 years of data on a generally healthy working population (4,121 men, 2,877 women; various working environments) obtained from the annual health check-ups to clarify the effects of continuing and discontinuing smoking on the development of CKD signs of proteinuria and/or a reduced GFR.

\section{Subjects and methods}

The study cohort comprised 7,964 working individuals (4,637 men, 3,327 women) recruited from a total of 20,782 people working in 447 various kinds of workplaces located in Ishikawa prefecture, Japan; however, it was not a randomized population. The 20,782 workers had their serum creatinine (Cr) concentrations measured in 2003 as part of the annual health check-up program in their respective workplace carried out by an occupational health service organization; 7,964 (38.3\%) of these same individuals had their $\mathrm{Cr}$ concentrations measured again in 2009 by the same organization. Many young workers of the original population were not tested in 2009. However, nearly $70 \%$ of the workers aged $\geq 40$ years repeated the test in 2009 .
Health check-up

Individuals presenting for the health check-up were asked to refrain from smoking for $30 \mathrm{~min}$ or longer prior to the health check-up. Height and weight were measured with jacket and shoes removed, and $0.5 \mathrm{~kg}$ was subtracted from the measured weight in April-September and $1.0 \mathrm{~kg}$ in October-March for the net body weight. Body mass index (BMI) was calculated as the net body weight $(\mathrm{kg}) / \mathrm{height}$ $\left(\mathrm{m}^{2}\right)$. Blood pressure (BP) was measured by experienced nurses with an automatic manometer (UM-15P; ParamaTech Co., Fukuoka, Japan), with the person in the sitting position after resting on a chair for 5 min or longer. The Japanese Industrial Standard-sized arm-cuff was used except for persons with an arm girth of $\geq 34 \mathrm{~cm}$ for whom a larger arm-cuff used. The cuff position was maintained at the heart level during the measurement. $\mathrm{BP}(\mathrm{mmHg})$ was graded into six levels of "optimal BP" $(<120$ and $<80)$, "normal BP" ( $<130$ and <85), "high-normal BP" (130-139 and/or 85-89), "grade I hypertension" (140-159 and/or 90-99), "grade II hypertension" (160-179 and/or 100-109), and "grade III hypertension" ( $\geq 180$ and/or $\geq 110)$ according to the guidelines of the Japanese Society of Hypertension (JSH) [15] and scored 1-6, respectively, for BP levels. Urine samples were analyzed immediately after collection for protein concentration semi-quantitatively using a dipstick of Uro-paper III distributed by Eikenkagaku Co., Tokyo, Japan.

Venous blood samples were cooled on ice immediately after collection and conveyed to a laboratory for analyses within 4 h. Hemoglobin A1c (HbA1c) level (\%) in blood was first measured by the standard methods proposed by Japan Diabetes Society (JDS) using an automatic analyzer (model HLC-723G8; Tosoh Co., Tokyo, Japan) and then estimated as a National Glycohemoglobin Standardization Program (NGSP) equivalent value using the formula: HbA1c $($ NGSP $)=$ HbA1c $(J D S)+0.4$ [16]. Plasma samples were analyzed for glucose concentration (PG) using an automatic analyzer (model GA1170; Arkray, Kyoto, Japan. Individuals with a fasting $\mathrm{PG}$ of $126 \mathrm{mg} / \mathrm{dL}$, postprandial PG of $200 \mathrm{mg} / \mathrm{dL}$, and/or HbA1c of $\geq 6.5 \%$ were diagnosed as having DM. Further, a fasting PG of $110 \mathrm{mg} / \mathrm{dL}$, postprandial PG of $140 \mathrm{mg} / \mathrm{dL}$, and/or $\mathrm{HbA} 1 \mathrm{c}$ of $\geq 5.8 \%$ were defined as impaired glucose regulation (IGR).

Serum samples were analyzed for lipid concentrations, including total cholesterol (Tchol), low-density lipoprotein cholesterol (LDLc), high-density lipoprotein cholesterol (HDLc), and triglycerides (TG), using an automatic analyzer (model HITACHI-7700; Hitachi High-Technology Co., Tokyo, Japan). Subjects were defined to have dyslipidemia, such as high cholesterolemia (hChol) when they had a Tchol of $\geq 220 \mathrm{mg} / \mathrm{dL}$ or LDLc of $\geq 140 \mathrm{mg} / \mathrm{dL}$, low HDL cholesterolemia (IHDLc) when they had a HDLc of $<40 \mathrm{mg} / \mathrm{dL}$, and high triglyceridemia (hTG) when they 
had a TG of $\geq 150 \mathrm{mg} / \mathrm{dL}$ in fasting serum or $\geq 250 \mathrm{mg} / \mathrm{dL}$ in postprandial serum. Serum $\mathrm{Cr}$ concentration was also measured by the automatic analyzer with an enzyme assay kit (N-Assay L CRE-K; Nittobo Medical Co., Tokyo, Japan). The GFR was estimated (eGFR) using the equation proposed by the JSN as follows: eGFR $=194 \times($ age $\left.(\text { year })^{-0.287}\right) \times\left(\mathrm{Cr}(\mathrm{mg} / \mathrm{dL})^{-1.094}\right)[\times 0.739$ if female $]$ [17].

\section{Definition of CKD stages}

The Kidney Disease: Improving Global Outcomes (KDIGO) organization [18] classified the levels of GFR as follows: GFR of $\geq 90 \mathrm{~mL} / \mathrm{min} / 1.73 \mathrm{~m}^{2}$ was "normal", $60-89.9 \mathrm{~mL} / \mathrm{min} / 1.73 \mathrm{~m}^{2}$ was "mildly depressed", $30-59.9 \mathrm{~mL} / \mathrm{min} / 1.73 \mathrm{~m}^{2}$ was "moderately depressed", $15-29.9 \mathrm{~mL} / \mathrm{min} / 1.73 \mathrm{~m}^{2}$ was "severely depressed", and $<15 \mathrm{~mL} / \mathrm{min} / 1.73 \mathrm{~m}^{2}$ indicated "renal failure" level. It further defined the stages of CKD as: stage I, kidney damage (pathological abnormalities and/or abnormalities in blood and urine, and on imaging scans) with "normal" GFR; stage II, kidney damage with "mildly depressed" GFR; stage III, "moderately depressed" GFR irrespective of kidney damage; stage IV, "severely depressed" GFR; stage V, "renal failure" level GFR. No kidney damage with a GFR of $\geq 60 \mathrm{~mL} / \mathrm{min} / 1.73 \mathrm{~m}^{2}$ was defined as "free of CKD".

The subjects in our study were categorized into CKD stages in accordance with the definitions of the KDIGO for further analysis. However, it should be noted that the categorization in our subjects was based on single measurements of proteinuria and eGFR although the clinical definition of CKD requires CKD signs to be detectable for $\geq 3$ months. Among the subjects with normal eGFR, those showing an eGFR of $\geq 105 \mathrm{~mL} / \mathrm{min} / 1.73 \mathrm{~m}^{2}$, the upper $5 \%$ of the distribution in our subjects, were defined as having an elevated eGFR. The subjects who had proteinuria with an elevated eGFR as well as those with a normal eGFR were categorized into stage I CKD. None of our subjects had a low eGFR corresponding to stage V CKD or the renal failure level.

\section{Definition of smoking status}

Data on cigarette and alcohol consumption were obtained by interview by experienced nurses, as described in our previous studies [9, 11]. Smoking habits were classified into four categories, namely, lifelong non-smokers, exsmokers, current smokers consuming up to one pack per day, and smokers consuming more than one pack per day. For the sake of further analyses, the subjects were then categorized into three groups of smoking status: those who smoked at the 2009 health check-ups were defined as "continuous smokers" irrespective of smoking status in 2003, although most of them had smoked in 2003 as well; those who did not smoke in either 2009 or 2003 irrespective of past smoking before 2003 were defined as "nonsmokers"; those who had smoked in 2003 but did not smoke in 2009, thus quitting at any time from 2003 to 2009, were defined as "ex-smokers".

Usual alcohol consumption was categorized into four levels, i.e., essentially "non-drinkers" who did not drink alcoholic beverages during the last year or drank less than once a month on average, "mild drinkers" who drank once a month or more but less than $70 \mathrm{~mL}$ of ethanol per week on average, "moderate drinkers" who consumed 70-209 mL per week on average, and "heavy drinkers" who consumed $\geq 210 \mathrm{~mL}$ per week; these categories were scored 1-4, respectively, for alcohol consumption.

The subjects were further classified into five occupational categories, i.e., clerks (category 1), managers or professionals (category 2), machine operators or motorvehicle drivers (category 3), service or sales workers (category 4), and other occupations, including security guards, farmers and unclassified jobs (category 5).

\section{Data analyses}

Of the 7,964 subjects, those whose data for body weight (37 men, 50 women), urinalysis ( 2 men, 114 women), or PG (7 men) were not available were excluded. We also excluded 13 men and five women who declared a past history of primary kidney disease, such as glomerulonephritis or nephrotic syndrome, 252 men and 50 women who showed a high PG consistent with the diagnostic criteria of DM, and 28 men and 12 women who showed severe (grade III) hypertension (BP level 6) at the 2003 health check-ups. Among the remaining 4,298 men and 3,096 women, those who showed CKD signs at the 2003 health check-ups were also excluded, i.e., 51 men and 19 women with proteinuria and $121 \mathrm{men}$ and 112 women having an eGFR of $<60 \mathrm{~mL} /$ $\min / 1.73 \mathrm{~m}^{2}$. In addition, five men and 88 women who did not undergo urinalysis at the 2009 health check-ups were excluded. The final study cohort comprised 6,998 working individuals $(4,121$ men, 2,877 women, $87.9 \%$ of the original subjects) for whom we had a complete data set and who were free of health problems markedly affecting renal function and CKD signs in 2003. These individuals were defined as generally healthy subjects and analyzed for the association between smoking status from 2003 to 2009 and the development of CKD in 2009.

All statistical analyses were performed using a package of IBM SPSS Statistics ver. 19 (distributed by IBM Japan, Tokyo, Japan). Simple associations between the three categories of smoking status and the development of various stages of CKD in male and female workers were tested by 
$\chi^{2}$ tests. Multiple logistic regression (MLR) analyses were performed to examine the independence of the associations after adjusting for the effects of possible confounders, such as sex, age, BMI levels 1-4, BP levels 1-5, alcohol consumption levels $1-4$, the presence of IGR and dyslipidemia, and the five occupational categories. The changes in eGFR from 2003 to 2009 were compared in male and female workers belonging to the three groups of smoking status and between those developing or not developing proteinuria in 2009 using generalized linear model (GLM) analyses adjusted for the confounders.

In this study, we analyzed the data anonymized in an unlinkable fashion provided by an occupational health service organization. The study was approved by the ethics committee of Kanazawa Medical University.

\section{Results}

The profiles of the 4,121 men and 2,877 women at the 2003 health check-ups are summarized in Table 1. The mean, standard deviation (SD), and range of age of the male and female workers were 41.2, 9.7, and 18-71 years, and 42.3, 9.3 , and 18-69 years, respectively; the majority of study participants of both sexes were middle aged (mostly 30-59 years). The mean, SD, and range of the BMI in the male and female workers were $23.2,3.1$, and $15.5-43.8 \mathrm{~kg} /$ $\mathrm{m}^{2}$, and $21.7,3.1$, and $13.2-41.1 \mathrm{~kg} / \mathrm{m}^{2}$, respectively. The prevalence of overweight and obesity, grades I and II hypertension, and abnormal blood biochemistry test results of IGR, hChol, lHDLc, and hTG are shown in Table 1. The mean, SD, and range of eGFR in the male and female workers were $83.3,12.9$, and $60-228 \mathrm{~mL} / \mathrm{min} / 1.73 \mathrm{~m}^{2}$, and $84.2,14.5$ and $60-198 \mathrm{~mL} / \mathrm{min} / 1.73 \mathrm{~m}^{2}$, respectively, and slightly higher in females.

\section{Smoking status and development of CKD}

Proteinuria was detected in 60 men $(1.5 \%)$ and 21 women $(0.7 \%)$ in the 2009 annual health check-up. A "moderately depressed" eGFR of $30-59.9 \mathrm{~mL} / \mathrm{min} / 1.73 \mathrm{~m}^{2}$, corresponding to stage III CKD, was detected in 443 men $(10.7 \%)$ and 356 women $(12.4 \%)$. A more marked reduction of GFR, corresponding to stage IV or V CKD, was not found in any of the subjects. As shown in Table 2, male continuous smokers more frequently developed stages I and II CKD (1.6\%) than non-smokers $(0.8 \%)$ and exsmokers $(1.1 \%)$. Alternatively, continuous smokers showed a lower development of stage III CKD (8.2\%) than non-smokers $(12.8 \%)$ and ex-smokers $(12.8 \%)$. The distributions of the CKD stages according to the three groups of smoking status were significantly different $\left(\chi^{2}\right.$ test, $p<0.01$ ), and stage III CKD was significantly lower
Table 1 Profiles of the subjects at the 2003 health check-ups

\begin{tabular}{|c|c|c|}
\hline Variables & $\begin{array}{l}\text { Men } \\
(n=4,121) \\
n(\%)\end{array}$ & $\begin{array}{l}\text { Women } \\
(n=2,877) \\
n(\%)\end{array}$ \\
\hline \multicolumn{3}{|l|}{ Age (years) } \\
\hline$\leq 29$ & $587(14.2)$ & $344(12.0)$ \\
\hline $30-59$ & $3,473(84.3)$ & $2,484(86.3)$ \\
\hline$\geq 60$ & $61(1.5)$ & $49(1.7)$ \\
\hline \multicolumn{3}{|l|}{ BMI $\left(\mathrm{kg} / \mathrm{m}^{2}\right)$} \\
\hline$\leq 18.4$ & $161(3.9)$ & $356(12.4)$ \\
\hline $18.5-24.9$ & $2,920(70.9)$ & $2,122(73.8)$ \\
\hline $25.0-29.9$ & $928(22.5)$ & $348(12.1)$ \\
\hline$\geq 30.0$ & $112(2.7)$ & $51(1.8)$ \\
\hline \multicolumn{3}{|l|}{ Blood pressure $(\mathrm{mmHg})$} \\
\hline$<120$ and $<80$ & $1,245(30.2)$ & $1,629(56.6)$ \\
\hline$<130$ and $<85$ & $1,419(34.4)$ & 739 (25.7) \\
\hline $130-139$ and/or $85-89$ & $691(16.8)$ & $242(8.4)$ \\
\hline $140-159$ and/or $90-99$ & $631(15.3)$ & $227(7.9)$ \\
\hline $160-179$ and/or $100-109$ & $135(3.3)$ & $40(1.4)$ \\
\hline \multicolumn{3}{|l|}{ Blood chemistry test ${ }^{\mathrm{a}}$} \\
\hline IGR & $226(5.5)$ & $70(2.4)$ \\
\hline hChol & $978(23.7)$ & $650(22.6)$ \\
\hline lHDLc & $342(8.3)$ & $93(3.2)$ \\
\hline hTG & $755(18.3)$ & $48(1.7)$ \\
\hline \multicolumn{3}{|l|}{ eGFR $\left(\mathrm{mL} / \mathrm{min} / 1.73 \mathrm{~m}^{2}\right)$} \\
\hline$\geq 105.0$ & $238(5.8)$ & $227(7.9)$ \\
\hline $90.0-104.9$ & $900(21.8)$ & 535 (18.6) \\
\hline $60.0-89.9$ & $2,983(72.4)$ & $2,115(73.5)$ \\
\hline \multicolumn{3}{|l|}{ Cigarettes } \\
\hline Never smoked & $1,028(24.9)$ & $2,539(88.3)$ \\
\hline Ex-smoker & 904 (21.9) & $57(2.0)$ \\
\hline Smoke up to 1 pack/day & $1,540(37.4)$ & $273(9.5)$ \\
\hline Smoke $>1$ pack/day & 649 (15.7) & $8(0.3)$ \\
\hline \multicolumn{3}{|l|}{ Alcohol } \\
\hline Usually not drinking & $1,246(30.2)$ & $2,088(72.6)$ \\
\hline Up to $69 \mathrm{~mL} /$ week of ethanol & $1,474(35.8)$ & $673(23.4)$ \\
\hline 70-209 mL/week & $1,256(30.5)$ & $108(3.8)$ \\
\hline$>70-209 \mathrm{~mL} /$ week & $145(3.5)$ & $8(0.3)$ \\
\hline \multicolumn{3}{|l|}{ Occupation } \\
\hline Clerks & $1,000(24.3 \%)$ & $1,129(39.2 \%)$ \\
\hline Managers/professionals & $1,144(27.8 \%)$ & $600(20.9 \%)$ \\
\hline Operators/drivers & $1,223(29.7 \%)$ & $342(11.9 \%)$ \\
\hline Service/sales & $636(15.4 \%)$ & $656(22.8 \%)$ \\
\hline Others & $118(2.9 \%)$ & $150(5.2 \%)$ \\
\hline
\end{tabular}

$B M I$ body mass index, $e G F R$ estimated glomerular filtration rate

a The blood chemistry tests are defined in the text in the section Health check-up

$(p<0.01)$ in the male continuous smokers. In female workers, stages I and II CKD were also found more frequently in the continuous smoker group $(1.4 \%)$ than 
Table 2 Development of chronic kidney disease (CKD; stages I-III ${ }^{\mathrm{a}}$ ) during the 6-year study period in workers considered to be generally healthy who were free of CKD signs beforehand

\begin{tabular}{|c|c|c|c|c|c|c|c|c|}
\hline \multirow[t]{2}{*}{ Smoking status ${ }^{\mathrm{b}}$} & \multicolumn{4}{|c|}{ Male workers } & \multicolumn{4}{|c|}{ Female workers } \\
\hline & Total $n$ & $\begin{array}{l}\text { Stage } \mathrm{I}^{\mathrm{c}} \\
n(\%)\end{array}$ & $\begin{array}{l}\text { Stage } \text { II }^{\mathrm{c}} \\
n(\%)\end{array}$ & $\begin{array}{l}\text { Stage } \mathrm{III}^{\mathrm{c}, \mathrm{d}} \\
n(\%)\end{array}$ & Total $n$ & $\begin{array}{l}\text { Stage } \mathrm{I}^{\mathrm{c}} \\
n(\%)\end{array}$ & $\begin{array}{l}\text { Stage II }{ }^{\mathrm{c}} \\
n(\%)\end{array}$ & $\begin{array}{l}\text { Stage } \mathrm{III}^{\mathrm{c}, \mathrm{d}} \\
n(\%)\end{array}$ \\
\hline Non-smokers & 1,806 & $0(0.0)$ & $14(0.8)$ & $231(12.8)$ & 2,570 & $0(0.0)$ & $10(0.4)$ & $321(12.5)$ \\
\hline Ex-smokers & 459 & $1(0.2)$ & $4(0.9)$ & $59(12.8)$ & 78 & $0(0.0)$ & $0(0.0)$ & $8(10.2)$ \\
\hline Continuous smokers & 1,856 & $4(0.2)$ & $26(1.4)$ & $153(8.2)$ & 229 & $1(0.4)$ & $2(1.0)$ & $27(11.8)$ \\
\hline Total & 4,121 & $5(0.1)$ & $44(1.1)$ & 443 (10.7) & 2,877 & $1(<0.1)$ & $12(0.4)$ & $356(12.4)$ \\
\hline
\end{tabular}

${ }^{a}$ CKD stages are defined in section Definition of CKD stages

b Non-smokers: those who had never smoked until 2009; ex-smokers, those who had smoked in 2003 but quit smoking at any time between 2003 and 2009; continuous smokers, those who continued smoking from 2003 to 2009 or started smoking at any time during the study period

c The distributions of the CKD stages I-III among the three groups of smoking status were significantly different in both male and female workers $\left(\chi^{2}=28.84, d f=6, p<0.01\right.$ and $\chi^{2}=13.52, d f=6, p=0.04$, respectively)

${ }^{\mathrm{d}}$ Stage III CKD was significantly lower in male continuous smokers $\left(\chi^{2}=22.11, d f=2, p<0.01\right)$ but not different in females $\left(\chi^{2}=0.43\right.$, $d f=2, p=0.81)$

Table 3 Results of multiple logistic regression analyses on the association of variables with the development of CKD signs

\begin{tabular}{|c|c|c|c|c|}
\hline \multirow[t]{2}{*}{ Variables $^{\mathrm{a}}$} & \multicolumn{2}{|l|}{ Proteinuria } & \multicolumn{2}{|l|}{ Low eGFR ${ }^{b}$} \\
\hline & Odds ratio $(95 \% \mathrm{CI})$ & $p$ & Odds ratio $(95 \% \mathrm{CI})$ & $p$ \\
\hline Sex (women/men) & $1.06(0.57-1.98)$ & 0.859 & $1.02(0.84-1.24)$ & 0.866 \\
\hline Age (year) & $1.02(0.99-1.05)$ & 0.134 & $1.08(1.07-1.09)$ & $<0.001$ \\
\hline BMI levels (1-4) & $1.82(1.27-2.59)$ & 0.001 & $1.37(1.19-1.57)$ & $<0.001$ \\
\hline Blood pressure levels (1-5) & $1.33(1.10-1.62)$ & 0.004 & $0.97(0.90-1.04)$ & 0.347 \\
\hline IGR & $2.35(1.19-4.65)$ & 0.014 & $0.84(0.59-1.18)$ & 0.312 \\
\hline hChol & $1.46(0.90-2.36)$ & 0.130 & $1.06(0.90-1.27)$ & 0.480 \\
\hline 1HDLc & $1.33(0.64-2.79)$ & 0.449 & $0.92(0.65-1.29)$ & 0.625 \\
\hline hTG & $1.20(0.68-2.13)$ & 0.533 & $1.44(1.14-1.80)$ & 0.002 \\
\hline hGFR & $1.35(0.52-3.45)$ & 0.538 & $0.05(0.01-0.22)$ & $<0.001$ \\
\hline Smoking status (vs. non-smokers) & & 0.002 & & 0.006 \\
\hline Ex-smokers & $1.29(0.48-3.42)$ & 0.614 & $1.05(0.78-1.41)$ & 0.735 \\
\hline Continuous smokers & $2.52(1.50-4.25)$ & 0.001 & $0.74(0.60-0.90)$ & 0.003 \\
\hline Alcohol consumption levels (1-4) & $0.87(0.66-1.16)$ & 0.349 & $0.87(0.78-0.97)$ & 0.009 \\
\hline Occupations (1-5) & $1.01(0.84-1.21)$ & 0.941 & $0.98(0.92-1.04)$ & 0.433 \\
\hline
\end{tabular}

CI confidence interval

a Variables are defined in the section Subjects and methods

b eGFR of $<60 \mathrm{~mL} / \mathrm{min} / 1.73 \mathrm{~m}^{2}$

among non-smokers $(0.4 \%)$ and ex-smokers $(0.0 \%)$, and stage III CKD in female smokers was, similar to that in men, more prevalent in the non-smoker group (12.5\%) than among the ex-smokers $(10.2 \%)$ and continuous smokers $(11.8 \%)$. The distributions of CKD stages were significantly different $(p=0.04)$ in the three groups of smoking status but not significantly different $(p=0.81)$ for the development of stage III CKD in females.

For the sake of convenience for further discussion, the association between smoking status and development of proteinuria, instead of stages I and II CKD, and that between smoking status and development of a low eGFR (30-59 $\mathrm{mL} / \mathrm{min} / 1.73 \mathrm{~m}^{2}$; stage III CKD) were examined for independence by MLR analyses adjusting for the possible confounding factors. In addition, "elevated" eGFR (hGFR) was included in the variables to be examined for its effect on the future development of proteinuria and low GFR. The results are shown in Table 3. Sex and the presence of hChol and lHDLc as well as the five occupational categories were not significantly related to either the 
development of proteinuria or low eGFR. With respect to proteinuria, continuous smokers showed a significantly high odds ratio (OR) of 2.52 with a $95 \%$ confidence interval (CI) of 1.50-4.25, and ex-smokers showed an OR of 1.29 (95\% CI 0.48-3.42) in comparison with nonsmokers. In addition, BMI and BP levels, as well as the presence of IGR showed significant promoting effects on the development of proteinuria. hGFR had no significant effects on the development of proteinuria.
In terms of low eGFR, continuous smokers had a significantly low OR of 0.74 (95\% CI $0.60-0.90)$ and ex-smokers had an OR of 1.05 (95\% CI 0.78-1.41) in comparison with non-smokers. Age, BMI, and hTG were found to have significant promoting effects on the development of a low eGFR, while alcohol consumption was found to have a significant protective effect. In addition, hGFR had a strong protective effect on the development of low eGFR, with an OR of 0.05 (95\% CI 0.01-0.22).

Table 4 Results of multiple logistic regression analyses on the association of variables with the development of proteinuria in the study participants excluding those with impaired glucose regulation, grade I and II hypertension, and obesity, respectively

\begin{tabular}{|c|c|c|c|c|c|c|}
\hline \multirow[t]{2}{*}{ Variables $^{\mathrm{a}}$} & \multicolumn{2}{|c|}{ Subjects $\mathrm{A}^{\mathrm{b}}$ (proteinuria, $n=70$ ) } & \multicolumn{2}{|c|}{ Subjects $\mathrm{B}^{\mathrm{c}}$ (proteinuria, $n=43$ ) } & \multicolumn{2}{|c|}{ Subjects $C^{\mathrm{d}}$ (proteinuria, $n=37$ ) } \\
\hline & Odds ratio $(95 \% \mathrm{CI})$ & $p$ & Odds ratio $(95 \% \mathrm{CI})$ & $p$ & Odds ratio $(95 \% \mathrm{CI})$ & $p$ \\
\hline Sex (women/men) & $0.91(0.47-1.75)$ & 0.908 & $0.98(0.44-2.18)$ & 0.959 & $1.09(0.47-2.56)$ & 0.842 \\
\hline Age (year) & $1.02(0.99-1.05)$ & 0.227 & $1.01(0.98-1.05)$ & 0.449 & $1.02(0.98-1.06)$ & 0.369 \\
\hline BMI levels & $1.83(1.26-2.66)$ & 0.002 & $2.03(1.24-3.33)$ & 0.005 & $1.11(0.56-3.72)$ & 0.763 \\
\hline Blood pressure levels & $1.37(1.11-1.69)$ & 0.003 & $0.87(0.57-1.35)$ & 0.547 & $0.87(0.54-1.39)$ & 0.555 \\
\hline hChol & $1.54(0.91-2.59)$ & 0.108 & $2.15(1.11-4.16)$ & 0.023 & $2.37(1.16-4.83)$ & 0.017 \\
\hline 1HDLc & $1.45(0.66-3.17)$ & 0.352 & $1.40(0.50-3.94)$ & 0.525 & $1.20(0.34-4.30)$ & 0.776 \\
\hline hTG & $1.20(0.64-2.26)$ & 0.563 & $1.23(0.53-2.86)$ & 0.627 & $1.47(0.58-3.72)$ & 0.418 \\
\hline hGFR & $1.44(0.56-3.72)$ & 0.450 & $1.25(0.37-4.23)$ & 0.716 & $1.44(0.42-4.93)$ & 0.558 \\
\hline Smoking status & & 0.007 & & 0.086 & & 0.126 \\
\hline Ex-smokers & $1.22(0.41-3.60)$ & 0.723 & $0.85(0.19-3.80)$ & 0.828 & $0.44(0.06-3.42)$ & 0.432 \\
\hline Continuous smokers & $2.45(1.39-4.32)$ & 0.002 & $2.14(1.03-4.46)$ & 0.041 & $1.94(0.89-4.26)$ & 0.098 \\
\hline Alcohol consumption levels & $0.89(0.65-1.22)$ & 0.459 & $0.79(0.52-1.21)$ & 0.275 & $0.75(0.47-1.19)$ & 0.217 \\
\hline Occupations & $1.02(0.83-1.24)$ & 0.867 & $0.98(0.76-1.26)$ & 0.850 & $0.92(0.69-1.21)$ & 0.534 \\
\hline
\end{tabular}

a 3,895 male and 2,807 female workers without IGR

b 3,227 males and 2,553 females without IGR and grade I + II hypertension

c 3,165 males and 2,521 females without IGR, grade I + II hypertension and obesity (BMI of $\geq 30$ )

${ }^{\mathrm{d}}$ Variables are defined in the section Subjects and methods

Table 5 Mean and standard deviations of $\operatorname{eGFR}^{\mathrm{a}}$ and those of the change $(\Delta)$ during the 6-year study period

\begin{tabular}{llrlrr}
\hline Sex & Smoking status & $n$ & 2003 & $\begin{array}{l}2009 \\
\text { Mean } \pm \text { SD }\end{array}$ & $\begin{array}{l}\Delta 2003-2009 \\
\text { Mean } \pm \text { SD }\end{array}$ \\
\hline Men & Total & 4,121 & $83.3 \pm 12.9$ & $72.6 \pm 10.8$ & $10.6 \pm 9.2$ \\
& Non-smokers & 1,806 & $81.7 \pm 12.7$ & $71.2 \pm 10.4$ & $10.4 \pm 9.3$ \\
& Ex-smokers & 459 & $83.9 \pm 12.5^{\mathrm{c}}$ & $71.6 \pm 10.1$ & $12.3 \pm 9.2^{\mathrm{c}}$ \\
& Continuous smokers & 1,856 & $84.6 \pm 13.1^{\mathrm{c}}$ & $74.2 \pm 11.1^{\mathrm{c}}$ & $10.4 \pm 9.2^{\mathrm{e}}$ \\
Women & Total & 2,877 & $84.2 \pm 14.5^{\mathrm{d}}$ & $73.1 \pm 12.1^{\mathrm{d}}$ & $11.0 \pm 11.5$ \\
& Non-smokers & 2,554 & $84.0 \pm 14.6$ & $73.0 \pm 12.1$ & $10.9 \pm 11.6$ \\
& Ex-smokers & 78 & $87.9 \pm 14.7^{\mathrm{c}}$ & $75.9 \pm 13.4$ & $12.0 \pm 11.3$ \\
& Continuous smokers & 229 & $85.1 \pm 13.6$ & $73.4 \pm 11.6$ & $11.6 \pm 10.8$
\end{tabular}

${ }^{\text {a }}$ The differences in the means of eGFR $\left(\mathrm{mL} / \mathrm{min} / 1.73 \mathrm{~m}^{2}\right)$ and the changes were tested between men and women and among the three groups of smoking status by a two-way analysis of variance. Subsequent paired comparisons were performed by a least square difference method

b For the definitions of smoking status, see footnote "b" of Table 2

c Significant difference from non-smokers

d Significant difference between men and women

e Significant difference from ex-smokers 
Table 4 shows the results of the MLR analyses in all subjects, excluding those with IGR (group A, Table 4), grade I and II hypertension (group B, Table 4), and obesity (BMI $\geq 30$ ) (group $\mathrm{C}$, Table 4). In the subjects of $\mathrm{A}$ excluding those showing IGR in 2003, the OR of proteinuria in the continuous smokers was decreased to 2.45 (CI 1.39-4.32) but remained significant. In the subjects of B further excluding those showing grade I and II hypertension, the OR was decreased to 2.14 (CI 1.03-4.46) but significant. In the subjects of $\mathrm{C}$ further excluding obese subjects with a BMI of 30 or above, the OR of 1.94 (CI 0.89-4.26) was not significant. In these analyses hChol was shown to be a significant factor promoting the development of proteinuria rather than BP and BMI levels. No marked changes were observed in the association between continuous smoking and the low incidence of low eGFR even after excluding the subjects with IGR, hypertension and obesity.

\section{Smoking status and GFR reduction}

Table 5 shows the mean eGFR at the 2003 and 2009 health check-ups and the changes during the 6-year period in the male and female workers according to smoking status. Female workers had a significantly higher mean eGFR than male workers in both 2003 and 2009. However, the 6-year changes, 10.6 and $11.0 \mathrm{~mL} / \mathrm{min} / 1.73 \mathrm{~m}^{2}$ in male and female workers, respectively, were not significantly different. Male ex-smokers and continuous smokers, most of whom had smoked in 2003, were found to have a significantly higher mean eGFR than non-smokers in 2003. In 2009, continuous smokers still showed a higher eGFR than non-smokers, but ex-smokers no longer showed a higher eGFR. A significantly higher eGFR was observed in female ex-smokers but not in the continuous smokers in 2003. The reduction in eGFR during the 6-year period was significantly larger in ex-smokers than in non-smokers and continuous smokers in men; in women, the reduction in eGFR was largest among ex-smokers, similar to that found for men, but the differences were not significant.

Although the results are not shown in the table, a GLM analysis was performed in the male and female workers to examine the independent effects of developing proteinuria in 2009 and smoking status on the reduction of eGFR in the 6 -year with adjustment for possible confounders. The interactive effect between the development of proteinuria and smoking status on the eGFR values was not significant in either sex and thus not included in the model equations. Male workers who developed proteinuria showed a significantly larger reduction of eGFR than those who did not develop proteinuria ( $p=0.005$ ), namely, by $3.41 \mathrm{~mL} / \mathrm{min} /$ $1.73 \mathrm{~m}^{2}$, irrespective of smoking status. In female subjects, those who developed proteinuria also showed a lager reduction of eGFR than those who did not, namely, by $2.66 \mathrm{~mL} / \mathrm{min} / 1.73 \mathrm{~m}^{2}$. The difference was, however, not significant.

\section{Discussion}

A high risk of proteinuria in smokers

This 6-year observational study on mostly middle-aged, generally healthy male and female workers who had been free of CKD signs at the beginning of the study period demonstrated that those who continued smoking during the study period, irrespective of sex, had a 2.5-fold higher risk of developing proteinuria than those who did not smoke. The risk for developing proteinuria among those who quit smoking during the study period decreased to approximately $50 \%$ of that of continuous smokers. These findings confirm that chronic smoking contributes to the development of CKD, mainly stage I or II CKD, even in generally healthy middle-aged persons in the workplace and that quitting smoking substantially reduces this risk.

Subsequent analyses among the subjects excluding those with IGR, grade I and II hypertension, and obesity, respectively, showed that the development of proteinuria was strongly related to these major cardiovascular risk factors. These results imply that efforts aimed at preventing $\mathrm{CKD}$ in the general population should involve a combination of approaches, including improving other lifestyle factors and the proper use of medicines for improving metabolism and BP control, as well as the cessation of smoking. At the same time, our results suggest that the risk of developing proteinuria is at least twofold higher among apparently healthy middle-aged smokers. A recently published study on 10,118 Japanese male workers aged 40-55 years [19] showed a 1.5-fold risk of proteinuria in smokers during the 6-year observational period. The somewhat higher risk in our study may reflect the presence of subjects aged 56 years and older.

The risk of low GFR in smokers

In comparison with non-smokers, continuous smokers showed a significantly lower risk of developing stage III CKD, a GFR of $<60 \mathrm{~mL} / \mathrm{min} / 1.73 \mathrm{~m}^{2}$. There was a tendency for smokers to have a higher GFR than non-smokers. Our findings of a higher GFR and a lower risk of low GFR in smokers are consistent with those reported previously for general populations, especially in studies on workplaces [8-10, 12]. Our results confirm that the elevated GFR in smokers was caused by smoking since a large reduction in GFR was observed after individuals stopped smoking. The ex-smokers, however, did not show an excessive risk of 
developing a low GFR, suggesting that the reduction of GFR after quitting smoking does not necessarily mean impaired renal function.

The male and female workers in our study showed an average reduction in the eGFR of 10.6 and $11.0 \mathrm{~mL} / \mathrm{min} /$ $1.73 \mathrm{~m}^{2}$, respectively, during the 6-year study period. Although the reduction of eGFR was not different between smokers and non-smokers, the subjects who developed proteinuria during this period showed a larger reduction than those who did not, irrespective of smoking, namely, by 3.41 and $2.66 \mathrm{~mL} / \mathrm{min} / 1.73 \mathrm{~m}^{2}$ in males and females, respectively, although the difference was only significant in men. These findings suggest that although the GFR in smokers was even higher than that in smokers, it would ultimately decline more in smokers since the risk of developing proteinuria was twofold higher or more among smokers. This proposal should be examined in detail in further studies.

\section{The fate of elevated GFR in smokers}

Yoon et al. [12] proposed that most smokers in the healthy general population, including those showing an elevated GFR, would not show any renal functional deterioration in their lifetime, while only a small, susceptible subset of the same general population would show both a low GFR and proteinuria. These authors drew their conclusions from the findings of a cross-sectional study in mostly middle-aged participants of a large-scale health screening program in Korea. More specifically, the association between smoking and GFR was entirely different between those with a GFR of $\geq 50 \mathrm{~mL} / \mathrm{min} / 1.73 \mathrm{~m}^{2}$ and those with a lower GFR: a higher GFR in smokers was observed only among those subjects showing the higher GFR, but smokers inversely tended to have a lower GFR among those subjects with a lower GFR. However, the inverse association of smoking with eGFR between those showing the higher and lower eGFR, respectively, was not confirmed in our study cohort: the eGFR was higher in smokers than in non-smokers in both those subjects showing an eGFR of $\geq 60 \mathrm{~mL} / \mathrm{min} /$ $1.73 \mathrm{~m}^{2}$ and those showing a lower eGFR. The proposal of Yoon et al. [12] thus requires confirmation in future studies.

Alternatively, the elevated GFR in smokers might be an early sign of renal dysfunction. Orth and Hallan [2] have extensively discussed possible mechanisms underlying the development of CKD in smokers, including heavy metal toxicity due to inhalation of tobacco smoke [20-22], intrarenal vasoconstriction [23-27], and oxidative stress and the inflammatory process [28-30]. Based on the relatively copious body of evidence from previous studies, glomerular hypertension due to intrarenal vasoconstriction seems the most plausible mechanism, which is in turn related to a stimulated renin-angiotensin-aldosterone system (RAAS) caused by the nicotine inhaled with the cigarette smoke. This elevation of the GFR via a stimulated RAAS has been confirmed experimentally in dogs to which nicotine was administered [31], and it may be a sign of glomerular hyperfiltration and early stage renal damage similar to that observed in diabetic nephropathy [32]. However, in our study, an elevated GFR in smokers was not related to the future development of proteinuria and low GFR. This proposed mechanism has therefore not been confirmed. The role of elevated GFR in smokers should be elucidated by longer term observations.

Mild alcohol consumption had a significant protective effect on the reduction of GFR in our study cohort, which is consistent with the findings in our previous cross-sectional study [9]. The anti-atherogenic property of mild alcohol consumption [33-35] may have even had a protective role on renal function.

\section{Limitations of the study}

In addition to the limitations related to the sensitivity of dipstick-measured proteinuria, the validity of eGFR using the JSN equation [9], and the single measurements of those parameters, the selection of the study subjects should also be considered a limitation in our study. Japanese companies are mandated to have their workers aged 35-40 years or older take annual health check-ups, including blood tests of liver enzyme activities and serum lipid concentrations. The measurement of serum $\mathrm{Cr}$ is an option in these checkups. The subjects of our study were thus assumed to work for companies that can afford to have their workers be tested for serum $\mathrm{Cr}$ level. However, most of the companies were small or medium-sized private enterprises. We therefore considered our participants not to be special but generally representative of the middle-aged working population in Japan.

Of the total of 20,782 workers who had their serum $\mathrm{Cr}$ measured in 2003, only 7,964 (38.3\%) had it measured again in 2009. Participation rates of the employees in the annual health check-ups were as high as $95 \%$ or more in most of the workplaces included in our study, and incidental drop-outs were not common. The majority of the drop-outs are likely to have been relatively young workers because of the optional choice of blood tests and elderly ones because of the mandatory retirement age. It is reasonable to assume that the elderly workers who remained in the study were generally in better health than those who retired and dropped out of the study. Drop-outs due to sick leave or health-associated resignation from their place of employment may have occurred, and those in poor health must be more vulnerable to the toxic effects of smoking. To sum up, the unintentional drop-out subjects in this retrospective study are not considered to have exaggerated 
the strength of the association of smoking with the development of CKD.

Based on our results, it can be concluded that continuing smoking causes a twofold or higher risk of developing proteinuria in mostly middle-aged healthy workers in both sexes, while quitting smoking substantially reduces the risk. This 6-year observational study may be too short to reveal the risk of developing stage III or more severe forms of CKD in smokers from the working population.

Conflict of interest This work was supported by KAKENHI, a Grant-in-Aid for Scientific Research (C), 2010, from the Japan Society for the Promotion of Science (JSPS).

\section{References}

1. Orth SR. Effects of smoking on systemic and intrarenal hemodynamics: influence on renal function. J Am Soc Nephrol. 2004;15[Suppl 1]:S58-63.

2. Orth SR, Hallan SI. Smoking: a risk factor for progression of chronic kidney disease and for cardiovascular morbidity and mortality in renal patients - absence of evidence or evidence of absence? Clin J Am Soc Nephrol. 2008;3:226-36.

3. Orth SR, Ogata H, Ritz E. Smoking and the kidney. Nephrol Dial Transplant. 2000;15:1509-11.

4. Orth SR, Ritz E, Schrier RW. The renal risks of smoking. Kidney Int. 1997;51:1669-77.

5. Jones-Burton C, Seliger SL, Scherer RW, Mishra SI, Vessal G, Brown J, et al. Cigarette smoking and incident chronic kidney disease: a systematic review. Am J Nephrol. 2007;27:342-51.

6. Imai E, Horio M, Iseki K, Yamagata K, Watanabe T, Hara S, et al. Prevalence of chronic kidney disease (CKD) in the Japanese general population predicted by the MDRD equation modified by a Japanese coefficient. Clin Exp Nephrol. 2007;11:156-63.

7. Noborisaka Y. Smoking and chronic kidney disease (CKD) in generally healthy populations. Nephrol Urol Monogr. 2012;5 (in press).

8. Ishizaka N, Ishizaka Y, Toda E, Shimomura H, Koike K, Seki G, et al. Association between cigarette smoking and chronic kidney disease in Japanese men. Hypertens Res. 2008;31:485-92.

9. Noborisaka Y, Ishizaki M, Nakata M, Honda R, Yamada Y, Yokoyama $\mathrm{H}$, et al. Cigarette smoking, proteinuria, and renal function in middle-aged Japanese men from an occupational population. Environ Health Prev Med. 2012;17:147-56.

10. Sauriasari R, Sakano N, Wang DH, Takaki J, Takemoto K, Wang $\mathrm{B}$, et al. C-reactive protein is associated with cigarette smokinginduced hyperfiltration and proteinuria in an apparently healthy population. Hypertens Res. 2010;33:1129-36.

11. Yamada Y, Noborisaka Y, Ishizaki M, Honda R, Tsuritani I, Yamada S. Association between cigarette consumption and proteinuria in healthy Japanese men and women from an occupational population. J Occup Health. 2004;46:365-73.

12. Yoon HJ, Park M, Yoon H, Son KY, Cho B, Kim S. The differential effect of cigarette smoking on glomerular filtration rate and proteinuria in an apparently healthy population. Hypertens Res. 2009;32:214-9.

13. Miyatake N, Shikata K, Makino H, Numata T. Relationship between estimated glomerular filtration rate (eGFR) and metabolic syndrome in Japanese. Acta Med Okayama. 2010;64:203-8.

14. Tozawa M, Iseki K, Iseki C, Oshiro S, Ikemiya Y, Takishita S. Influence of smoking and obesity on the development of proteinuria. Kidney Int. 2002;62:956-62.
15. Ogihara T, Kikuchi K, Matsuoka H, Fujita T, Higaki J, Horiuchi M, et al. The Japanese Society of Hypertension guidelines for the management of hypertension (JSH 2009). Hypertens Res. 2009;32:3-107.

16. Kashiwagi A, Kasuga M, Araki E, Oka Y, Hanafusa T, Ito H, et al. International clinical harmonization of glycated hemoglobin in Japan: from Japan Diabetes Society to National Glycohemoglobin Standardization Program values. Diabetol Int. 2012;3:8-10.

17. Matsuo S, Imai E, Horio M, Yasuda Y, Tomita K, Nitta K, et al. Revised equations for estimated GFR from serum creatinine in Japan. Am J Kidney Dis. 2009;53:982-92.

18. Levey AS, Eckardt KU, Tsukamoto Y, Levin A, Coresh J, Rossert $\mathrm{J}$, et al. Definition and classification of chronic kidney disease: a position statement from kidney disease: improving global outcomes (KDIGO). Kidney Int. 2005;67:2089-100.

19. Maeda I, Hayashi T, Sato KK, Koh H, Harita N, Nakamura Y, et al. Cigarette smoking and the association with glomerular hyperfiltration and proteinuria in healthy middle-aged men. Clin J Am Soc Nephrol. 2011;6:2462-9.

20. Barbier O, Jacquillet G, Tauc M, Cougnon M, Poujeol P. Effect of heavy metals on, and handling by, the kidney. Nephron Physiol. 2005;99:105-10.

21. EL-Safty IA, Afifi AM, Shouman AE, EL-Sady AK. Effects of smoking and lead exposure on proximal tubular integrity among Egyptian industrial workers. Arch Med Res. 2004;35:59-65.

22. Satarug S, Moore MR. Adverse health effects of chronic exposure to low-level cadmium in foodstuffs and cigarette smoke. Environ Health Perspect. 2004;112:1099-103.

23. Benck U, Clorius JH, Zuna I, Ritz E. Renal hemodynamic changes during smoking: effects of adrenoreceptor blockade. Eur J Clin Invest. 1999;29:1010-8.

24. Grassi G, Seravalle G, Calhoun DA, Bolla GB, Giannattasio C, Marabini M, et al. Mechanisms responsible for sympathetic activation by cigarette smoking in humans. Circulation. 1994;90:248-53.

25. Halimi JM, Philippon C, Mimran A. Contrasting renal effects of nicotine in smokers and non-smokers. Nephrol Dial Transplant. 1998;13:940-4.

26. Ritz E, Benck U, Franek E, Keller C, Seyfarth M, Clorius J. Effects of smoking on renal hemodynamics in healthy volunteers and in patients with glomerular disease. J Am Soc Nephrol. 1998;9:1798-804.

27. Ritz E, Benck U, Orth SR. Acute effects of cigarette smoking on renal hemodynamics. Contrib Nephrol. 2000;130:31-8.

28. Cucina A, Corvino V, Sapienza P, Borrelli V, Lucarelli M, Scarpa $\mathrm{S}$, et al. Nicotine regulates basic fibroblastic growth factor and transforming growth factor beta1 production in endothelial cells. Biochem Biophys Res Commun. 1999;257:306-12.

29. Esmatjes E, Flores L, Lario S, Claria J, Cases A, Inigo P, et al. Smoking increases serum levels of transforming growth factorbeta in diabetic patients. Diabetes Care. 1999;22:1915-6.

30. Mur C, Claria J, Rodela S, Lario S, Campistol JM, Titos E, et al. Cigarette smoke concentrate increases 8-epi-PGF2alpha and TGFbeta1 secretion in rat mesangial cells. Life Sci. 2004;75:611-21.

31. Pawlik WW, Jacobson ED, Banks RO. Actions of nicotine on renal function in dogs. Proc Soc Exp Biol Med. 1985;178:585-90.

32. Mogensen CE. Prediction of clinical diabetic nephropathy in IDDM patients. Alternatives to microalbuminuria? Diabetes. 1990;39:761-7.

33. Iso H, Kitamura A, Shimamoto T, Sankai T, Naito Y, Sato $\mathrm{S}$, et al. Alcohol intake and the risk of cardiovascular disease in middle-aged Japanese men. Stroke. 1995;26:767-73.

34. Marmot MG, Rose G, Shipley MJ, Thomas BJ. Alcohol and mortality: a U-shaped curve. Lancet. 1981;1:580-3.

35. Ronksley PE, Brien SE, Turner BJ, Mukamal KJ, Ghali WA. Association of alcohol consumption with selected cardiovascular disease outcomes: a systematic review and meta-analysis. Br Med J. 2011;342:d671. 